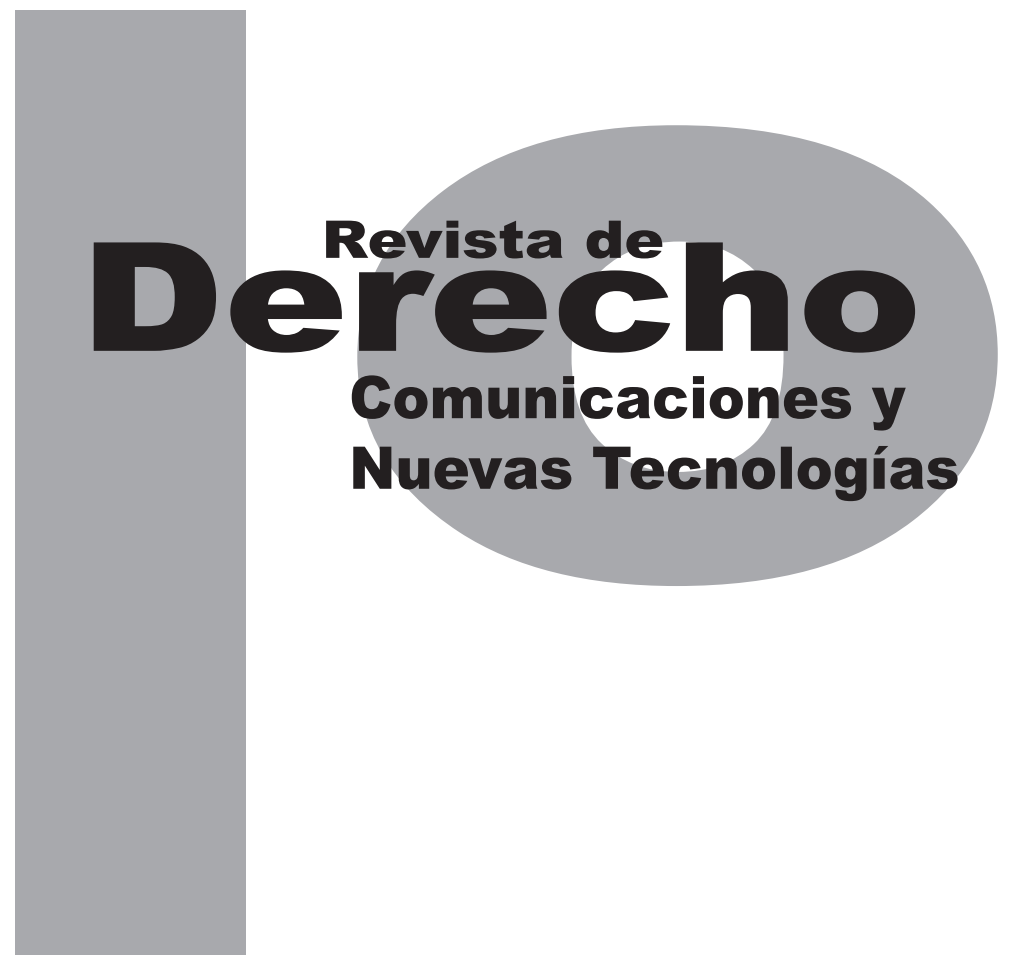

\title{
EL DERECHO AL OLVIDO: ANÁLISIS COMPARATIVO DE LAS FUENTES INTERNACIONALES CON LA REGULACIÓN COLOMBIANA
}

\author{
VALENTINA MANRIQUe Gómez
}

Artículo de reflexión

DOI: http://dx.doi.org/10.15425/redecom.14.2015.09

Universidad de los Andes

Facultad de Derecho

Rev. derecho comun. nuevas tecnol.

No. 14, julio - diciembre de 2015. ISSN 1909-7786 


\section{El derecho al olvido: análisis comparativo de las fuentes internacionales con la regulación colombiana}

\section{Resumen}

El derecho al habeas data tiene dentro de sus alcances el derecho a la caducidad del dato, del que se deriva el derecho al olvido, también llamado derecho a la caducidad del dato negativo, que consiste en la potestad del titular de pedir la exclusión de un dato negativo de una base de datos en un término prudencial, para así salvaguardar su derecho al buen nombre y su dignidad. Lo anterior, con el objetivo de analizar la regulación colombiana y compararla con los regímenes internacionales.

Palabras clave: protección de datos personales, habeas data, tratamiento de datos, caducidad, derecho al olvido, oNU, CE, UE, OEDE, RIPDP, OEA, Colombia, fotografía, derecho de autor.

\section{The right to be forgotten: a comparative analysis of international sources with colombian regulations}

\section{Abstract}

The right to habeas data has within its scope the right to data expiration, from which the right to be forgotten is derived, also called the right to expiration of negative data, which consists of the data owner's power to request the exclusion of negative data from a database within a reasonable term, in order to safeguard his/her right to a good reputation and dignity. This is looked at in order to analyze and compare Colombian regulations with international rules.

Keywords: personal data protection, habeas data, data processing, expiration, right to be forgotten, UN, EC, EU, EAW, RIPDP, OAS, Colombia, photography, copyright.

\section{O direito ao esquecimento: análise comparativo das fontes internacionais com a regulação colombiana}

Resumo

$\mathrm{O}$ direito ao habeas data tem dentro de seus alcances o direito à caducidade do dado, do que se deriva o direito ao esquecimento, também chamado direito à caducidade do dado negativo, que consiste na potestade do titular de pedir a exclusão de um dado negativo de uma base de dados em um termo prudencial, para assim salvaguardar seu direito ao bom nome e sua dignidade. 0 anterior, com o objetivo de analisar a regulação colombiana e compará-la com os regimes internacionais.

Palavras-chave: proteção de dados pessoais, habeas data, tratamento de dados, caducidade, direito ao esquecimento, ONU, CE, UE, OEDE, RIPDP, OEA, Colômbia, fotografia, direito de autor. 


\title{
El derecho al olvido: análisis comparativo de las fuentes internacionales con la regulación colombiana*
}

\author{
Valentina Manrique Gómez**
}

\begin{abstract}
SUMARIO
Introducción - I. EL DERECHO AL OLVIDO EN COLOMBIA - A. Definición y evolución histórica - B. Análisis jurisprudencial del derecho al olvido en Colombia - II. EL DERECHO AL OLVIDO EN LOS DOCUMENTOS DE ORGANISMOS INTERNACIONALES - A. Reglamento general de protección de datos de la Comisión Europea - B. Directiva 95/46 de la Comisión Europea - C. Asia-Pacific Economic Cooperation (APEC) - D. Organización de las Naciones Unidas - E. Organización para la Cooperación y el Desarrollo Económicos - F. Red Iberoamericana de Protección de Datos - G. Organización de Estados Americanos - III. ANÁLISIS COMPARATIVO SOBRE LA REGULACIÓN DEL DERECHO AL ALVIDO - IV. EL DERECHO AL OLVIDO EN EL CASO DE LAS FOTOGRAFÍAS - A. Una perspectiva desde la regulación de derechos de autor - B. Una perspectiva desde la regulación de Protección de Datos (Ley 1581 de 2012) - C. Una perspectiva desde la jurisprudencia - V. CONCLUSIÓN - Referencias.
\end{abstract}

\footnotetext{
* Cómo citar este artículo: Manrique Gómez, V. (Diciembre, 2015). El derecho al olvido: análisis comparativo de las fuentes internacionales con la regulación colombiana. Revista de Derecho, Comunicaciones y Nuevas Tecnologías, 14. Universidad de los Andes (Colombia).
}

** Abogada de la Universidad de Los Andes con opción académica en periodismo. Correo electrónico: v.manrique503@gmail.com 
"Quien controla el pasado controla el futuro. Quien controla el presente controla el pasado."

George Orwell

\section{Introducción}

Alrededor del mundo las legislaciones sobre el tratamiento y la protección del derecho al habeas data incluyen de manera expresa el derecho a la cancelación (representado con la letra "c" en los derechos ARCo). ${ }^{1}$ De este se ha derivado el principio de caducidad o temporalidad de la información negativa, generalizado con la expresión derecho al olvido, que en definitiva responde a los principios de limitación en el tiempo y temporalidad de los datos personales negativos.

El derecho al olvido puede entonces definirse como aquel principio según el cual los datos negativos deben ser eliminados de las bases de datos, una vez ha transcurrido el tiempo establecido para su tratamiento, con el fin de que la persona no quede "prisioner[a] de su pasado" (Supervisor Europeo de Protección de Datos, 2011). Es decir, que una vez desaparecidas las causas que dieron nacimiento al dato negativo, o cuando ha transcurrido un tiempo razonable desde su publicación, término que normalmente está delimitado por la ley, este debe desaparecer.

El origen de este derecho está íntimamente ligado con la preocupación de la regulación de los

1 La denominación de derechos "arco" es un convencionalismo derivado de las iniciales de los cuatro principales derechos reconocidos especialmente en las leyes básicas de protección de datos: acceso, rectificación, cancelación y oposición. datos financieros; sin embargo, con el tiempo y el avance de las nuevas tecnologías su aplicación se ha ampliado a temas como los antecedentes penales, la información comercial y los datos sensibles en las redes sociales, en especial las fotografías.

Es clara la importancia de la regulación sobre la materia, pues se ha convertido en la herramienta de los titulares de los datos para proteger su intimidad, su dignidad, su buen nombre y la correcta utilización de sus datos personales, ya que de no existir, la información negativa mantenida en bases de datos de manera indefinida podría llegar a causar graves perjuicios para las personas y sus familiares.

Teniendo como referencia lo anterior, el objetivo de este trabajo es hacer un análisis del derecho al olvido en la regulación colombiana, con el fin de entender su significado, su aplicación y su evolución histórica, para luego compararlo con el entendimiento que hay sobre este derecho en los documentos de las entidades internacionales en materia de protección y manejo de datos personales.

Para lograr dicho objetivo, primero se expondrán de manera individual las posiciones sobre el tema de las diferentes fuentes de estudio, es decir, Colombia y los organismos internacionales, y se analizará la concepción y la aplicación que cada uno tiene sobre el derecho al olvido. Con base en ello se procederá a comparar los resultados en búsqueda de las diferencias y similitudes, para luego elaborar una construcción conceptual que explique de manera general y 
abstracta el comportamiento de los sistemas estudiados frente al derecho al olvido.

\section{EL DERECHO AL OLVIDO EN COLOMBIA}

\section{A. Definición y evolución histórica}

En Colombia la legislación en esta materia se inicia con la Constitución Política de 1991, que incluye en su artículo 15 el derecho fundamental al habeas data. A partir de ese momento y hasta el 2008 hay un desarrollo jurisprudencial sobre este derecho y los otros que se derivan de él, en más de veinte sentencias de la Corte Constitucional que inician con la T-414/92, y con las cuales se crea una doctrina en la materia y sobre los principios que han de regir el tratamiento de datos personales hasta el día de hoy.

En el 2008 se expide la Ley 1266, que regula el Tratamiento de datos financieros, norma que debe entenderse según las aclaraciones hechas por la Corte Constitucional en la sentencia C-1011 del mismo año. Más adelante, en el año 2012 se expide la Ley 1581, mejor conocida como Ley de Protección de Datos, que contiene las disposiciones generales sobre la materia, y debe leerse también según el entendimiento dado por la Corte en la sentencia C-748 del 2011. Finalmente, en el año 2013, el Gobierno nacional expidió el Decreto 1377, por medio del cual se determinan los procedimientos para la aplicación de la ley y se resuelven algunas dudas de esta.
A continuación se analizarán las mencionadas fuentes para ver el desarrollo que estas hacen del derecho al olvido.

La Constitución Política de Colombia en su artículo 15 introduce en el ordenamiento el derecho al habeas data, incluyendo en él ciertos derechos como son, "a conocer, actualizar y rectificar las informaciones que se hayan recogido sobre ellas en los bancos de datos y en archivos de entidades públicas y privadas". Sin embargo, en este artículo no se hace ninguna mención al derecho a la caducidad del dato o al derecho al olvido de la información negativa.

Posteriormente, la Corte Constitucional en la sentencia T-176 de 1995, con ponencia del magistrado Eduardo Cifuentes, delimitó el derecho de habeas data de la siguiente manera:

¿Cuál es el núcleo esencial del habeas data? A juicio de la Corte, está integrado por el derecho a la autodeterminación informática y por la libertad, en general, y en especial económica. La autodeterminación informática es la facultad de la persona a la cual se refieren los datos, para autorizar su uso y circulación, de conformidad con las regulaciones legales. Y se habla de libertad económica, en especial, porque ésta podría ser vulnerada al restringirse indebidamente en virtud de la circulación de datos que no sean veraces, o que no hayan sido autorizados por la persona concernida o por la ley.

Existe, además, el derecho a la caducidad del dato negativo, no consagrado expresamente en el artículo 15 de la Constitución, pero que se deduce de la misma autodeterminación 
informática, y también de la libertad. [Cursivas añadidas].

De ahí que la caducidad del dato negativo sea un derecho constitucional que puede tutelarse de manera directa, por ser parte del núcleo esencial del derecho de habeas data. Lo que además, concuerda con el artículo 28 de la Carta que establece que no pueden existir sanciones o penas imprescriptibles en el ordenamiento jurídico colombiano.

La primera mención del derecho al olvido, como tal, está en la sentencia T-414 de 1992, donde se decide sobre la caducidad de un dato negativo en el sistema financiero. En ella, bajo el epígrafe "La cárcel del alma y el derecho al olvido" la Corte sostiene que los datos personales por su relación con los derechos fundamentales no pueden tener vigencia ilimitada y los datos negativos no pueden tornarse perennes o indefinidos en el tiempo:

Los datos tienen por su naturaleza misma una vigencia limitada en el tiempo la cual impone a los responsables o administradores de bancos de datos la obligación ineludible de una permanente actualización a fin de no poner en circulación perfiles de "persona virtuales" que afecten negativamente a sus titulares, vale decir, a las personas reales.

De otra parte, es bien sabido que las sanciones o informaciones negativas acerca de una persona no tienen vocación de perennidad y, en consecuencia después de algún tiempo tales personas son titulares de un verdadero derecho al olvido (T-414/1992, C. Angarita).
Esta, sin duda alguna, es la sentencia madre para el impulso del derecho al olvido en Colombia, pues a partir de ella se inicia el desarrollo jurisprudencial sobre la materia, que en un primer grado solo se refería a la aplicación del derecho del olvido frente a los datos negativos en el sistema financiero.

Tres años más tarde, en la sentencia de unificación SU-082 de 1995, la Corte concretó el tema de la caducidad del dato financiero al precisar que los deudores del sistema financiero tienen derecho a que su información se actualice para contener los hechos nuevos que los benefician y fijar un límite razonable para la permanencia de los datos negativos, para que el deudor que pueda pagar sus deudas recupere su buen nombre.

En esta sentencia la Corte exhorta al legislador a reglamentar el derecho al habeas data y determinar el límite temporal de los datos negativos. Pero mientras este lo hace impone unos términos para evitar el abuso del poder informativo y defender el interés general, a saber:

- Cuando se trate de un pago voluntario de la obligación, el dato negativo ha de mantenerse por un término de dos años a partir del pago. Este término se explica porque "al fin y al cabo, pagó voluntariamente, y se le reconoce su cumplimiento, aunque haya sido tardío". Exceptúa la Corte los casos en los que la mora haya sido menor a un año, en cuya situación el término de caducidad del dato será igual al doble del tiempo de la mora. Esto aplica siempre y cuando no se hayan reportado nuevos incumplimientos del mismo deudor con otras obligaciones entre las partes. 
- Si el pago se ha producido como consecuencia de un proceso ejecutivo, a pesar de que el dato sea público debe tener un término de caducidad, que será de cinco (5) años, que es el mismo término fijado para la prescripción de la pena para los delitos que no tienen señalada pena privativa de la libertad en el Código Penal. Sin embargo, cuando el pago se ha producido una vez presentada la demanda, con la sola notificación del mandamiento de pago, el término de caducidad será solamente de dos (2) años, es decir, se seguirá la regla general del pago voluntario.

Aun así, esta no fue la única sentencia en la que la Corte aplicó el derecho al olvido, pues con el paso del tiempo empezaron las tutelas alegando este derecho frente a los antecedentes Penales, y para tutelarlo dicha corporación debió analizar los casos según la clasificación de datos personales. Concluye entonces afirmando que estos son datos personales en la medida en que asocian una situación determinada a una persona natural, lo que hace que puedan identificarla o singularizarla. Adicionalmente, que se trata de datos negativos, ya que "asocia el nombre de una persona con la ruptura del pacto social, con la defraudación de las expectativas normativas, con la violación de los bienes jurídicos fundamentales" (CConst., C-185/2003, E. Montealegre).

Frente a la aplicación del derecho al olvido en antecedentes penales, la Corte aclara que esto solo es posible cuando se ha cumplido la pena o esta ha prescrito. Sin embargo, la facultad de suprimir estos datos en particular no es absoluta, ni incluye la desaparición total de la información de la base de datos.
Es claro que la conservación de los antecedentes penales cumple finalidades constitucionales y legales legitimas a las que esta Corte ha hecho constante referencia (moralidad de la función pública, aplicación de la ley penal, actividades de inteligencia, ejecución de la ley). Por tanto, considera la Corte que no hace parte del derecho de habeas data, en su modalidad suprimir, la facultad de exigir al administrador de la base de datos sobre antecedentes penales, la exclusión total y definitiva de tales antecedentes. En este caso, no hay, en los términos de la sentencia T-414 de 1992, un derecho al olvido como tal. No lo puede haber, al menos, mientras subsistan las finalidades constitucionales del tratamiento de este tipo específico de información personal. (CConst., T-414/1992, C. Angarita).

Sin embargo, ante este dilema la Corte reitera que a pesar de no ser posible aplicar un derecho al olvido en la totalidad, sí es deber del Estado proteger el derecho de habeas data de los ciudadanos. Para ello llegó a una solución intermedia:

El administrador responsable de la base de datos sobre antecedentes penales que, para los casos de acceso a dicha información por parte de particulares, en especial, mediante el acceso a la base de datos en línea a través de las plataformas respectivas de la Internet, omita emplear cualquier fórmula que permita inferir la existencia de antecedentes penales en cabeza de los peticionarios, si efectivamente estos no son requeridos por, ni tienen cuentas pendientes con las autoridades judiciales. (CConst., SU-458/2012, A. Guillén).

Después de este precedente jurisprudencial y constitucional, llama la atención que la Ley 
1266 de 2006, ley de tratamiento de datos financieros, no contempla expresamente el derecho al olvido ni la caducidad del dato negativo como derechos de los titulares del dato, teniendo en cuenta que el derecho al olvido tuvo su mayor auge frente al dato financiero; sin embargo, el numeral 2.1. del artículo 6, concerniente a los derechos de los titulares del dato frente a las fuentes de la información, establece que los primeros tendrán el derecho de "ejercer los derechos fundamentales al hábeas data y de petición", lo que significa que incluye la posibilidad de ejercer este derecho, aunque no se refiera a él de manera particular.

No obstante, el artículo 13 habla sobre la permanencia del dato y cambia el precedente jurisprudencial en la materia, por lo siguiente:

La información de carácter positivo permanecerá de manera indefinida en los bancos de datos de los operadores de información.

Los datos cuyo contenido haga referencia al tiempo de mora, tipo de cobro, estado de la cartera, y en general, aquellos datos referentes a una situación de incumplimiento de obligaciones, se regirán por un término máximo de permanencia, vencido el cual deberá ser retirada de los bancos de datos por el operador, de forma que los usuarios no puedan acceder o consultar dicha información. El término de permanencia de esta información será de cuatro (4) años contados a partir de la fecha en que sean pagadas las cuotas vencidas o sea pagada la obligación vencida.

Este artículo fue materia de una larga discusión en la sentencia de constitucionalidad sobre los términos de caducidad, que terminó en la declaratoria de constitucionalidad, en el entendido que la caducidad del dato financiero, en caso de mora inferior a dos años, no podrá exceder el doble de la mora, y que el término de permanencia de cuatro años también se contará a partir del momento en que se extinga la obligación por cualquier modo.

Por otro lado, la ley general de protección de datos (Ley 1581 de 2012) incluye el derecho de caducidad en el literal e) del artículo octavo sobre derechos de los titulares, cuando habla sobre el derecho que estos tienen para solicitar la supresión del dato; sin embargo, condiciona esta solicitud a situaciones en las que no se respeten los principios, derechos y garantías constitucionales y legales, previa declaración de la Superintendencia de Industria y Comercio sobre dicha situación.

En la Ley 1266 de 2006, a pesar de no mencionarse de manera directa el derecho al olvido en cabeza de los titulares, la referencia a la garantía constitucional hace que este pueda entenderse como una de las situaciones que se pueden alegar para pedir la supresión del dato.

En conclusión, el derecho al olvido en el ordenamiento jurídico colombiano es una creación jurisprudencial que se deriva del núcleo esencial del artículo 15 de la Constitución Política del 91. Y es en la jurisprudencia de la Corte Constitucional donde se define y se delimita su aplicación, porque ninguna de las actuales leyes sobre el tratamiento de datos personales hace una mención explícita a este derecho de los titulares. 


\section{B. Análisis jurisprudencial del derecho al olvido en Colombia}

Como ya se dijo, en 1992 la Corte Constitucional produjo la sentencia T-414, la primera donde se trató el tema del derecho al olvido y desde entonces este derecho se ha tutelado de manera creciente. Sin embargo, dicho crecimiento no es continuo. A mayo del 2015, más de doscientas sentencias de este tribunal desarrollan el tema de protección y tratamiento de datos personales, y de ese número, aproximadamente un $3 \%$ tratan el derecho al olvido. La gráfica 1 muestra el número de sentencias, expedidas por las Cortes en esta materia.

Gráfico 1. Número de sentencias sobre el derecho al olvido expedidas por la Corte Constitucional

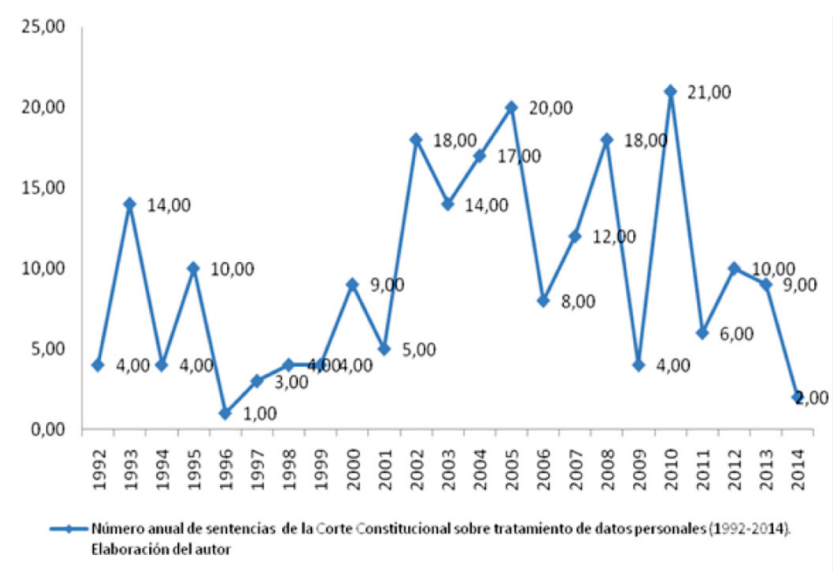

Fuente: cortesía del doctor Nelson Remolina.

Como se observa, el auge de tales sentencias es previo a la ley general de protección de datos personales (Ley 1581 de 2012).

El 47\% de dichas sentencias surgieron a raíz de obligaciones dinerarias (gráfica 2). En otras palabras, pedían la aplicación del derecho al olvido a partir de la Ley 1266 de 2008, ley de datos financieros.
Gráfico 2. Principales categorías de información analizadas en la jurisprudencia sobre tratamiento de datos personales de la Corte Constitucional (1992-2014)

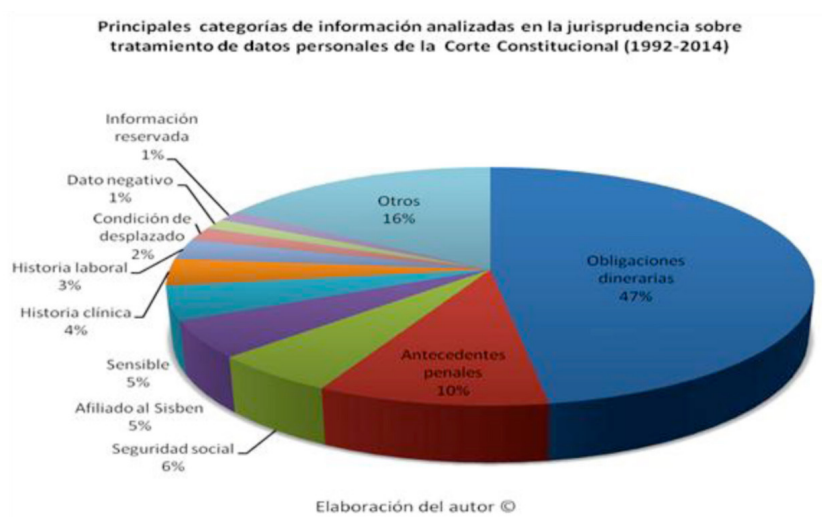

Fuente: cortesía del doctor Nelson Remolina.

Como se ve en la gráfica 2 , el otro 53\% corresponde a la aplicación del derecho al olvido asociado a datos personales no financieros. Dentro de este grupo predomina la tutela sobre los antecedentes penales y los datos relativos a la seguridad social.

A pesar de que el derecho al olvido no es el más tutelado por quienes protegen su derecho al habeas data, sí ha tenido un desarrollo jurisprudencial notable, de ahí su amplia influencia en la expedición de la ley sobre la materia.

\section{EL DERECHO AL OLVIDO EN LOS DOCUMENTOS DE ORGANISMOS INTERNACIONALES}

A continuación se procederá a hacer un análisis de las principales fuentes y documentos de autoridades internacionales sobre la protección de datos. 


\section{A. Reglamento general de protección de datos de la Comisión Europea}

La Comisión Europea está impulsando la configuración de un nuevo marco jurídico para la protección de los datos de las personas físicas, que derogaría la Directiva 95/46/CE, con el cual busca poner la regulación al día con los cambios que se han producido en la tecnología de la información y las comunicaciones, y en consecuencia una protección más efectiva frente al tratamiento internacional de datos, en especial en los grandes sistemas, como los motores de búsqueda.

En esta propuesta, contrario a lo que pasaba en la Directiva 95/46/CE, donde solo se establecía el derecho de supresión, se regula con rigor el derecho al olvido haciendo recaer la responsabilidad de la supresión del dato en quien lo haya publicado en Internet y no en los buscadores, lo que realmente es la aplicación de los derechos ARCo en esta red. Este derecho le atribuye al titular del dato la facultad para exigir que el responsable suprima los datos que ha publicado y se abstenga de continuar con su difusión cuando se ha agotado su finalidad o la autorización. Adicionalmente, el artículo 17 de esta propuesta incluye la obligación del responsable del tratamiento que haya difundido los datos personales, de informar a los terceros sobre la solicitud del interesado de suprimir todos los enlaces a los datos personales, copias o réplicas de estos.

Así mismo, la propuesta constriñe a los responsables de los datos a implementar los mecanismos tecnológicos necesarios para garantizarles a los titulares que se cumplan los plazos fijados para la supresión de los datos, algo muy parecido a lo que ha dicho la Corte Constitucional colombiana frente al derecho al olvido en el caso de los antecedentes penales. En la propuesta se especifican los límites del derecho al olvido cuando existe un deber legal de conservar los datos por motivos de interés público, pero siempre obligando a respetar los principios de finalidad y proporcionalidad. La Comisión Europea también regula este derecho frente a las actividades de los buscadores, imponiéndoles la obligación de hacer anónimas las búsquedas de los usuarios después de seis meses y eliminar las cookies.

En relación con la normativa colombiana, podría decirse que esta propuesta formaliza mucho más el derecho al olvido de los titulares del dato, pues el artículo 17 lo menciona directamente como "derecho al olvido", cosa que no ocurre en la legislación colombiana. Frente a las causas que podrían derivar en la aplicación, en principio encontramos las mismas: expiración de la finalidad del tratamiento, retiro del consentimiento y tratamientos contrarios a la ley. Con relación a los límites legales se encuentra la protección del orden público y las labores estatales, que es el mismo que menciona la Corte frente al tema de antecedentes penales. Además, se incluyen aquellos límites necesarios para el ejercicio del derecho a la libertad de expresión, los necesarios por motivos de salud pública, y aquellos usados con fines históricos, estadísticos o científicos.

Estos límites, si bien no están explícitamente mencionados en la jurisprudencia de la Corte 
Constitucional colombiana sobre el derecho al olvido, sí fueron incluidos en la Ley 1581 de 2012, como los casos en los cuales no es necesaria la autorización del titular para el tratamiento de datos, lo que hace pensar que se deben aplicar de igual forma frente a este derecho y por tanto sería igual que en la propuesta de Reglamento.

Podría decirse que ambas regulaciones parten de los mismos principios, pero su gran diferencia es el campo de aplicación: el reglamento está exclusivamente dirigido al derecho al olvido en Internet, mientras que en Colombia esta aplicación se centra en casos de datos financieros y antecedentes penales, sin ningún caso aún conocido sobre su aplicación a dicha red.

\section{B. Directiva 95/46 de la Comisión Europea}

Como se mencionó anteriormente, en esta decisión no se hace ningún tipo de alusión al derecho al olvido por parte de los titulares de los datos personales que se están tratando. Lo más cercano a esta figura es lo que establece el literal b) del artículo 12, Ilamado derecho a la supresión del dato personal, el cual está en el título de derechos de los titulares, y que al igual que la normativa colombiana prevé esta posibilidad cuando el tratamiento sea contrario a la ley o a la autorización: "la supresión o el bloqueo de los datos cuyo tratamiento no se ajuste a las disposiciones de la presente Directiva, en particular a causa del carácter incompleto o inexacto de los datos."
Sobre este tema ha dicho el abogado general del caso Google Spain SL vs. Agencia Española de Protección de Datos (2012), Sr. Niilo Jääskinen:

La Directiva no establece un derecho general al olvido, en el sentido de que un interesado esté facultado para restringir o poner fin a la difusión de datos personales que considera lesivos o contrarios a sus intereses. La finalidad del tratamiento y los intereses a los que sirve, al compararse con los del interesado, son los criterios que han de aplicarse cuando se procesan datos sin el consentimiento del interesado, y no las preferencias subjetivas de éste. Una preferencia subjetiva por sí sola no equivale a una razón legítima, en el sentido del artículo 14, letra a) (derecho de oposición), de la Directiva. (Sempere, 2013).

Sobre este punto ha dicho la Agencia Española de Protección de Datos (2014) que la Comisión Europea ha de clarificar los términos del derecho al olvido en la legislación. Sin embargo, para esta entidad el actual marco normativo europeo ofrece suficientes mecanismos para concretar este derecho en la práctica.

Entre estos mecanismos están, por un lado, una de las características fundamentales de todo consentimiento: que puede ser revocado; por el otro, el artículo 6.1.c) de la Directiva que establece expresamente que los datos objeto de tratamiento no podrán ser excesivos. Del mismo modo, el artículo 6.1.d) recoge que "deben tomarse todas las medidas razonables para que aquellos datos inexactos e incompletos (...) sean suprimidos o rectificados". Asimismo, el artículo 12.b) garantiza el derecho del interesado a obtener del responsable del tratamiento, 
“la rectificación, la supresión o el bloqueo de los datos cuyo tratamiento incompleto afecta otros derechos contenidos en la Decisión". E igualmente, el artículo 14 sanciona el denominado derecho de oposición.

Cree la Agencia Española que la adecuada combinación de estos mecanismos deberían permitir el goce efectivo del derecho al olvido, para todos los titulares de los datos en tratamiento.

A pesar de la opinión de la citada Agencia, es de anotar que la decisión no prevé este derecho para los titulares de los datos tratados, y ni siquiera fue concebido como una posibilidad en la regulación, ya que en ella solo se refiere y de manera muy ligera al derecho a la supresión. Muy diferente a lo que acontece en la legislación colombiana, pues aunque no hace parte de la ley como tal, si se creó el concepto de este derecho desde el núcleo esencial del habeas data, y jurisprudencialmente se desarrolló a tal nivel, que a pesar de no estar textualmente concebido se entiende presente en el ordenamiento jurídico.

\section{Asia-Pacific Economic Cooperation (APEC)}

El APEC Privacy Framework (en adelante, marco de privacidad), es la principal regulación sobre la protección de datos personales para los países vinculados a la APEC. En él se enuncian los principios para el tratamiento efectivo y legítimo de los datos personales por parte de las empresas y países. Sin embargo, en este documento no se hace mención al derecho al olvido de los datos; ni siquiera se menciona el derecho que tienen los titulares a pedir la supresión de sus datos. Esto es muy curioso, pues mencionan el derecho a conocer la información, rectificarla y actualizarla, pero jamás aluden a la posibilidad de eliminar los datos personales.

Es tal la inexistencia de esta posibilidad, que ni siquiera en los artículos que regulan la limitación sobre la recolección de los datos se plantea la opción de que cuando esta sea inadecuada o ilegal sea posible eliminarlos.

La única forma de entender este vacío es asumiendo que la APEC, como fondo para el desarrollo económico y la prosperidad, quisiera sobreponer las empresas a los consumidores, protegiendo su actividad empresarial sobre los datos personales, lo que resultaría absolutamente inadecuado e incorrecto.

Frente a la normativa colombiana, lo primero que corresponde aclarar es que este documento no es vinculante para el país, y si llegara a serlo sería obsoleto dado que nuestra regulación es mucho más completa frente a los derechos de los titulares de los datos, pues no solo incluye el derecho de cancelación, sino que además añade el derecho al olvido.

\section{Organización de las Naciones Unidas}

Para la onu la regulación sobre protección de datos personales versa sobre dos documentos: el artículo 12 de la Declaración Universal de Derechos Humanos y la Resolución 45/95 de 1990.

El primero dice: 
Nadie será objeto de injerencias arbitrarias en su vida privada, su familia, su domicilio o su correspondencia, ni de ataques a su honra o a su reputación. Toda persona tiene derecho a la protección de la ley contra tales injerencias o ataques.

Y la segunda establece los principios rectores para la reglamentación de los ficheros computarizados de datos. Ambas normativas están orientadas a la protección de la privacidad y la intimidad.

Es pertinente aclarar que estos documentos no son una regulación como tal, sino un conjunto de parámetros que toda ley de protección de datos debería tener. Es por ello que la Resolución solo contiene los principios derivados del artículo antes citado de la carta de derechos, es decir, los principios destinados a proteger la privacidad y la intimidad de las personas.

Por tratarse solo de principios, en esta resolución no vamos a encontrar una alusión directa al derecho al olvido. Sin embargo, en el artículo $3^{\circ}$ se incluye el principio de finalidad, que según su enunciado podría entenderse como el punto de partida para la creación de este derecho en legislaciones nacionales.

Lo anterior se sustenta en los literales a) y c) del artículo, que dicen: “a) Todos los datos personales reunidos y registrados siguen siendo pertinentes a la finalidad perseguida; c) El periodo de conservación de los datos personales no excede del necesario para alcanzar la finalidad con que se han registrado".
Estos literales se ajustan a lo dicho por la Corte Constitucional, como base para la creación de este derecho:

En este caso, en aras de preservar la intimidad y el buen nombre de un deudor añejo, debe aplicarse el denominado derecho al olvido, es decir, el principio según el cual determinados datos deben ser eliminados de los archivos transcurrido un espacio de tiempo establecido desde el instante en que se presentó el hecho referido, esto con el fin que el individuo no quede 'prisionero de su pasado'. (CConst., T-487/2004, J. Araújo).

Ello lo respalda el profesor Oscar Puccinelli:

La caducidad del dato negativo, que genera el derecho de su titular de reclamar su exclusión y que en un término más generalizado y absolutamente gráfico se conoce como el "derecho al olvido", que en definitiva corresponde a los principios de "limitación en el tiempo" y "finalidad" del tratamiento de datos personales (2012).

De ahí que aunque no haya una alusión directa al derecho, sí se establecen los principios generales de tratamiento que son la base para el desarrollo legal y jurisprudencial del derecho al olvido en Colombia y otras legislaciones del mundo.

\section{E. Organización para la Cooperación y el Desarrollo Económicos}

La Organización para la Cooperación y el Desarrollo Económicos (OCDE), en 2013 publicó su marco de privacidad (The OECD Privacy Fra- 
mework). En él, al igual que en el documento de la onu, se incluyen los principios que deben regir el tratamiento de datos personales.

Al tratarse de una compilación de principios, ocurre lo mismo que en el caso de la onu, por cuanto no hay una alusión directa al derecho en estudio, sino a los principios que dieron origen a este, uno de ellos el principio de uso limitado. A diferencia de los demás documentos antes estudiados, en este se hace una diferenciación entre el principio de recolección limitada y el principio de uso limitado.

Esta distinción permite, de manera más certera, identificar el principio que en teoría debería dar origen al derecho a la cancelación del dato y por ende al derecho al olvido. Dice el artículo 10 de ese documento, que los datos personales no deben ser revelados, accesibles o usados para fines diferentes a aquellos especificados para el momento de la recolección o aquellos autorizados por la ley:

10. Personal data should not be disclosed, made available or otherwise used for purposes other than those specified in accordance with Paragraph 9 except:

a) with the consent of the data subject; or

b) by the authority of law.

De ahí que, aunque no haya una alusión directa al derecho, sí se establecen los principios generales de tratamiento, que son la base para el desarrollo legal y jurisprudencial del derecho al olvido en Colombia y otras legislaciones del mundo.

\section{F. Red Iberoamericana de Protección de Datos}

La Red Iberoamericana de Protección de Datos (RIPD) es un foro permanente para el intercambio de información entre los países miembros, que permite involucrar a todos los sectores de la sociedad con el fin de promover los desarrollos normativos sobre la protección de datos. Como tal, no tiene un documento principal que regule la materia de datos personales. En el documento Directrices para la Armonización de la Protección de Datos en la Comunidad Iberoamericana, que como tal no es una regulación sino una recopilación de criterios y conclusiones sobre cómo se debe regular lo concerniente a los datos personales, no hay ninguna alusión al derecho al olvido. Otros documentos de la RIPD son las declaraciones de los encuentros. De ellas, solo la Declaración del XI Encuentro realizado el año 2013 en Cartagena de Indias (Colombia), menciona el derecho al olvido, y lo hace como uno de los compromisos de este encuentro:

Teniendo presentes los temas derivados de la edición número once del Encuentro y que requieren una puntual atención para garantizar el derecho a la protección de datos, tales como el derecho al olvido, las garantías de los datos personales en la nube (cloud computing), la publicidad en internet, los flujos transfronterizos de información, entre otros (RIPD, 2013, pág. 1).

Podría concluirse al respecto que si bien la mencionada autoridad no tiene una definición o posición clara respecto del derecho al olvido, lo reconoce como un derecho de los titulares y 
como un punto crítico de estudio y análisis para los países miembros y sus legislaciones.

También queda claro que la RIPD sigue la corriente de pensamiento europea, según la cual el derecho al olvido está íntimamente ligado a la información digital en la red o Internet.

\section{G. Organización de Estados Americanos}

El Comité Jurídico Interamericano de la OEA adoptó en marzo de este año la Propuesta de Declaración de Principios de Privacidad y Protección de Datos Personales en las Américas, mediante la Resolución CJI/RES 186. El objetivo de este documento es instar a los Estados miembros de la Organización a que adopten las medidas necesarias para respetar la privacidad, la reputación y la dignidad de las personas dentro de su territorio.

El cuarto principio, Uso Limitado y Retención, establece:

Los datos personales deben ser mantenidos y utilizados solamente de manera legítima no incompatible con el fin o fines para los cuales se recopilaron. No deberán mantenerse más del tiempo necesario para su propósito o propósitos y de conformidad con la legislación nacional correspondiente.

Para el Comité, el principio de retención limitada parte de la base de que los datos personales solo pueden mantenerse por el tiempo que sea necesario para el cumplimiento del fin para el cual fueron recolectados. Adicionalmente, argumenta que la realidad tecnológica moderna exige una limitación general a la retención de datos, ya que, como el costo del almacenamiento de datos ha bajado de manera considerable, es más económico para los administradores de datos mantenerlos indefinidamente en vez de examinarlos y borrar aquellos que no son necesarios. Dicha retención innecesaria y excesiva tiene evidentes afectaciones a la privacidad de los titulares de los datos.

Si bien la Propuesta de Declaración de Principios no incluye de manera textual o directa el derecho al olvido, sí contempla lo que en la legislación colombiana se entendería como el principio de necesidad y de temporalidad. Ello hace que los países miembros de la oEA cuenten con los principios básicos que dan lugar a que un individuo pueda alegar la eliminación de sus datos personales, cumpliendo con los requisitos para ello, lo que terminaría siendo una aplicación del derecho al olvido.

\section{ANÁLISIS COMPARATIVO SOBRE LA REGULACIÓN DEL DERECHO AL OLVIDO}

Después de lo visto en los capítulos anteriores se puede afirmar que el derecho al olvido cada vez cobra una mayor importancia en las regulaciones sobre protección y tratamiento de datos personales, especialmente por el auge de las nuevas tecnologías que han universalizado la información, lo que a su vez dificulta el control de los usuarios sobre sus datos personales.

A pesar de ello, este derecho como tal solo está incluido de manera explícita en una de las 
legislaciones estudiadas, esto es, la Propuesta de Reglamento de la Unión Europea. La gran tendencia en estos documentos es a reglamentar el principio de finalidad o necesidad, a partir del cual crean los parámetros del derecho al olvido, sin que esté como tal en la jurisdicción; lo que podría decirse es que es apenas un primer paso para tenerlo en cuenta en futuras regulaciones, y para permitir que se alegue tal derecho amparado en la protección que dan los principios.

Y finalmente está el caso colombiano, donde este derecho hace parte del ordenamiento jurídico, pero como una creación o desarrollo jurisprudencial que surge a partir de la concepción del derecho al olvido como núcleo esencial del derecho al habeas data consagrado en la Constitución Política, y que valga señalar, se ha incluido de manera indirecta en la nueva regulación de protección de datos.

Otro tema interesante que sobresale del presente estudio es la orientación que se le da a este derecho. Por orientación me refiero a la aplicación para la cual se ha concebido. En Colombia, este derecho surge como un mecanismo para eliminar los datos negativos del sistema financiero y después evoluciona a temas de antecedentes penales, lo que es lógico considerando que para la época en la que se desarrolló esta jurisprudencia Internet no tenía el auge que presenta hoy en día.

A pesar de lo anterior, y de ser Colombia pionera, pues desde 1992 creó y aplicó este concepto, solo hasta el 2012, es decir 22 años después, la Propuesta de Reglamento vuelve a mencionar el derecho al olvido de manera directa, dándole una aplicación clara y concreta, como es la información en Internet. Lo que queda claro es que la aplicación del Reglamento será la que rija a futuro, porque en otros temas ya hay un precedente normativo y jurisprudencial.

Otro punto muy interesante es que parecería que el tema del derecho al olvido solo está presente en regulaciones europeas o que han tenido influencia de su sistema de protección de datos, porque solo se encontró información en el Reglamento de Protección de Datos de la Comisión Europea; en la Iberoamericana de Protección de Datos; en la Declaración de la Agencia Española de Protección de Datos y en Colombia, cuya legislación tiene una gran influencia de Europa.

Esto es resultado de las nociones del sistema europeo de protección de datos, que es opuesto al estadounidense, pues mientras para el primero es un derecho fundamental, para los americanos es solo un derecho derivado de la ley del consumidor. Al tratarse de un derecho fundamental tiene una mayor protección y un desarrollo más completo, mientras que al ser un derecho derivado otorga menos posibilidades para mejorarlo o para crear mecanismos de protección adicionales a los que ya trae la ley del consumidor de Norteamérica.

\section{EL DERECHO AL OLVIDO EN EL CASO DE LAS FOTOGRAFÍAS}

Las nuevas tecnologías y la masificación de las redes sociales han facilitado la circulación de 
datos y fotografías por todo el mundo y por todas las redes, llegando al extremo de que las personas ya no pueden controlar los datos que circulan en Internet. Incluso han generado un nuevo fenómeno mundial denominado selfie, el cual se ha tomado las redes sociales de los famosos y de las personas del común. Sin embargo, este también ha contribuido a una sobreexposición de las personas y de su vida privada en las redes sociales, lo que puede resultar en una violación al derecho a la intimidad, el buen nombre, el habeas data e incluso la vida en familia.

Este fenómeno es de tal importancia y tiene tantas consecuencias para la sociedad, que los países ya están regulando ciertos aspectos en la materia. Un ejemplo de ello es Colombia, donde el proyecto de ley del Nuevo Código Nacional de Policía, que actualmente se discute en el Congreso de la República, incluye un capítulo sobre privacidad, con el cual se pretende regular la toma y circulación de fotografías en redes sociales.

Así pues, el Proyecto de Ley 99 del 2014, bajo el título IV, “De la tranquilidad y las relaciones respetuosas", en el capítulo primero, artículo 56, determina que habrá lugar a medidas correctivas (en este caso multas) para los siguientes comportamientos que afectan la privacidad de las personas:

2. Tomar fotografías o videos de personas o de sus bienes en actividades de carácter privado, personal o familiar, realizadas en lugar privado, y divulgarlas por cualquier medio con o sin fin de lucro, sin consentimiento expreso o salvo justificación legal.
3. Hacer públicas las imágenes privadas de una persona sin su consentimiento expreso o salvo justificación legal.

El postulado que se debate, entonces, limita la toma y circulación de fotografías siempre que sean de personas o sus bienes, en actividades privadas y que se realicen en un lugar privado, y además prohíbe divulgarlas en cualquier medio, sin autorización previa y expresa del titular de la imagen.

A raíz de estas prohibiciones surge una pregunta: ¿A quién pertenece la fotografía, esto es, a quien la toma o a quien sale en ella? La importancia de esta pregunta se fundamenta en que si la fotografía es de propiedad del autor, es decir, de quien toma la foto, no habría lugar a reclamar sobre ella el derecho al olvido. Sin embargo, si es un dato personal, habría derecho a pedir que dicha imagen deje de circular bajo determinados supuestos.

En principio podría decirse que en Colombia hay dos leyes nacionales que tienen en común su origen o mejor, inspiración, en leyes internacionales, como son la Ley 23 de 1982 sobre derechos de autor, el derecho a la imagen y la Ley Estatutaria 1581 de 2012 sobre protección de datos personales. Como una diferencia importante entre estas dos leyes hay que decir que la Ley 23 de 1982 es antigua en el ordenamiento, que se aplica en concordancia con la Decisión 351 del 2000, mientras que la Ley 1581 del 2012 es una ley nueva, cuya aplicación apenas está empezando y que a pesar de ser derivada de la normativa internacional, ninguna de sus fuentes aplica en Colombia. 


\section{A. Una perspectiva desde la regulación de derechos de autor}

El literal i) del artículo $4^{\circ}$ de la Decisión Andina 351 de 1993 reconoce la fotografía como objeto de protección por parte del derecho de autor. En ese mismo sentido el artículo 2 de la Ley 23 de 1982 señala:

Los derechos de autor recaen sobre las obras científicas, literarias y artísticas las cuales se [sic] comprenden todas las creaciones del espíritu en el campo científico, literario y artístico, cualquiera que sea el modo o forma de expresión y cualquiera que sea su destinación, tales como: los libros, folletos y otros escritos; las conferencias, alocuciones, sermones y otras obras de la misma naturaleza; las obras dramáticas o dramático-musicales; las obras coreográficas y las pantomimas; las composiciones musicales con letra o sin ella; las obras cinematográficas, a las cuales se asimilan las obras expresadas por procedimiento análogo a la cinematografía, inclusive los videogramas; las obras de dibujo, pintura, arquitectura, escultura, grabado, litografía; las obras fotográficas a las cuales se asimilan las expresadas por procedimiento análogo a la fotografía; las obras de arte aplicadas; las ilustraciones, mapas, planos, croquis y obras plásticas relativas a la geografía, a la topografía, a la arquitectura o a las ciencias, y, en fin, toda producción del dominio científico, literario o artístico que pueda reproducirse, o definirse por cualquier forma de impresión o de reproducción, por fonografía, radiotelefonía o cualquier otro medio conocido o por conocer. [Cursivas añadidas].

Ahora bien, una fotografía se considerará obra, siempre y cuando reúna los requisitos para ser calificada como tal, es decir, ser una creación intelectual original de naturaleza artística, susceptible de ser divulgada y reproducida de cualquier forma. En tal caso, la titularidad de la obra recaerá sobre su autor. De esta manera, todas las disposiciones contenidas en la Decisión Andina 351 de 1993 y en la Ley 23 de 1982 son aplicables a este tipo de obras. En ejercicio de derechos patrimoniales, el autor, o de ser el caso, el titular de la obra fotográfica puede, de manera exclusiva, autorizar o prohibir que la obra sea comunicada al público, reproducida, distribuida o transformada. Lo anterior debe entenderse sin perjuicio de los derechos a la imagen, intimidad o buen nombre de las personas, reconocidos en el artículo 15 de la Constitución Política.

Siguiendo con lo anterior, frente a los derechos de quien aparece en el retrato el artículo 87 de la Ley 23 de 1982 establece que para publicar un retrato de una persona se requiere de un consentimiento expreso que podrá ser revocado en cualquier momento, con la correspondiente indemnización de perjuicios.

De las normas anteriores queda claro que, la utilización del retrato para fines comerciales no es libre y, por lo tanto, para su reproducción se requiere la autorización previa y expresa de la persona que aparece en él o de sus causahabientes. Por consiguiente, el derecho del creador o autor de la fotografía está limitado por el derecho del habeas data de la persona cuya imagen aparece en dicha fotografía.

El importante analizar el artículo 87 de la Ley 23 de 1982, en su parte final, pues en principio 
permitiría revocar el consentimiento para el uso de la imagen, es decir, pedir que se suprima el uso de esta, siempre y cuando haya una indemnización de perjuicios. Con la aplicación de este artículo parecería que la regulación de derecho de autor es consecuente con el derecho al olvido y la protección de datos sensibles, pues permitiría al titular revocar la autorización y pedir la supresión de la imagen de las redes en las que circula.

\section{B. Una perspectiva desde la regulación de Protección de Datos} (Ley 1581 de 2012)

Según la Ley 1581 de 2012 y la sentencia C-748 de 2011, las fotografías son datos personales por

i) estar referido[s] a aspectos exclusivos y propios de una persona natural, ii) permitir identificar a la persona, en mayor o menor medida, gracias a la visión de conjunto que se logre con el mismo y con otros datos; iii) su propiedad reside exclusivamente en el titular del mismo, situación que no se altera por su obtención por parte de un tercero de manera lícita o ilícita, y iv) su tratamiento está sometido a reglas especiales (principios) en lo relativo a su captación, administración y divulgación.

Así mismo, las fotografías pueden ser consideradas como datos sensibles, ya que pueden afectar la intimidad de la persona, y su uso indebido puede llevar a la discriminación y la afectación de otros derechos fundamentales.

Por tratarse de un dato personal sensible, requiere un tratamiento especial que incluye autorización explícita para su uso. Siendo un dato personal, entonces está cubierta por todos los derechos que trae la ley de protección de datos y, en especial, el derecho al olvido, analizado en este trabajo.

\section{Una perspectiva desde la jurisprudencia}

Actualmente en Colombia no existe jurisprudencia que aplique el derecho al olvido como tal en un caso de uso de fotografías como datos personales. Como se mencionó anteriormente, este derecho ha sido ampliamente referido por la jurisprudencia en temas de antecedentes penales y reportes en centrales de crédito. Sin embargo hay un caso en particular, la sentencia de tutela T-260 de 2012) en donde se hace un tratamiento intensivo del derecho constitucional al habeas data, que resulta en aplicación por orden judicial del derecho al olvido.

El presente caso es una acción de tutela en que la madre de una menor de cuatro años reclama la protección de los derechos a la intimidad, el buen nombre y el libre desarrollo de la personalidad de su hija, que se ven violentados por su padre, ya que este abrió un perfil en la red social Facebook a nombre de la menor alterando la fecha de nacimiento, donde publica un álbum familiar virtual de la menor.

A raíz de este caso la Corte hace un estudio del derecho al habeas data entendiéndolo como:

La garantía del derecho a la intimidad, de allí que se hablara de la protección de los datos 
que pertenecen a la vida privada y familiar, entendida como la esfera individual impenetrable, en la que cada cual puede realizar su proyecto de vida y en la que ni el Estado ni otros particulares pueden interferir.

A su vez lo define como un derecho autónomo compuesto por la autodeterminación informática y la libertad:

Aquel que otorga la facultad al titular de datos personales, de exigir a las administradoras de datos personales el acceso, inclusión, exclusión, corrección, adición, actualización, y certificación de los datos, así como la limitación en las posibilidades de divulgación, publicación o cesión de los mismos, conforme a los principios que informan el proceso de administración de bases de datos personales. (CConst., T-729/2002, E. Montealegre).

Acto seguido hace énfasis en el riesgo que tienen las redes sociales para la protección de datos personales:

A pesar de que las redes sociales digitales generalista o de ocio y profesionales- se consolidan como un espacio en el que rigen normas similares a las del mundo no virtual, el acceso a las mismas acarrea la puesta en riesgo de derechos fundamentales, pues el hecho de que algunas de ellas se manejen a través de perfiles creados por los usuarios, por medio de los cuales se pueden hacer públicos datos e información personal, puede traer como consecuencia la afectación de derechos como la intimidad, la protección de datos, la imagen, el honor y la honra. (CConst., T-729/2002, E. Montealegre).
Para la Corte, los riesgos para los derechos fundamentales en las redes sociales pueden estar generados por tres situaciones:

1. Que hay una falta de conciencia de los usuarios sobre el hecho de que sus datos personales son accesibles por cualquier persona y que estos pueden tener un gran valor en el mercado.

2. Los datos personales pueden ser utilizados por otros usuarios de forma ilícita y malintencionada.

3. Es posible que se publique en la red información falsa o sin autorización del usuario.

De acuerdo con la Corte, en el caso de la sentencia T-260/12 el derecho al habeas data se encuentra afectado con la creación de la cuenta en Facebook sin que la menor sea consciente de ello, en especial el principio de libertad en el manejo de la información, máxime tratándose de datos personales de un sujeto especialmente protegido, como es un menor de edad.

A pesar de que no se estudia a fondo el tema de las fotografías, la Corte sí es clara en el hecho de que la circulación de datos personales, entre ellos fotografías en las redes sociales, sin autorización del titular del dato (en este caso de la imagen en la foto) constituye una vulneración al núcleo del derecho al habeas data. Razón por la cual el afectado tiene derecho a la remoción del dato y por ende a la aplicación del derecho al olvido.

Existe otro precedente constitucional en la materia: la sentencia T-634 de 2013. En ella se 
trata el caso de una masajista que se vinculó con una empresa de masajes y al momento de su vinculación le pidieron la autorización para tomarle unas fotografías con fines publicitarios. Después de terminado el contrato entre las partes, la masajista solicitó que retiraran sus fotografías de la página web y del perfil de Facebook de la empresa, solicitud que le fue denegada argumentando que tenían una autorización de uso de la imagen. Para la Corte el derecho a la imagen, el buen nombre, la honra, la intimidad y demás derechos fundamentales limitan el acuerdo de voluntad sobre una autorización de uso de imagen, razón por la cual se le ordenó a la empresa retirar las fotografías de sus redes sociales.

La Corte inicia el estudio de este caso analizando el derecho a la imagen e indicando:

El derecho a la imagen constituye un derecho autónomo, aun cuando también puede ser lesionado junto con los derechos a la intimidad, a la honra y al buen nombre de su titular, y que está estrechamente vinculado a la dignidad y libertad de la persona, amparados por el artículo 14 de la Constitución. (CConst., T-405/2007, J. Córdoba).

Con relación al consentimiento en particular, el Tribunal Constitucional ha establecido que el derecho de toda persona al manejo de su propia imagen implica la necesidad de consentimiento para su utilización, "en especial si se la explota publicitariamente” (T-471/1999, J. G. Hernández), aclarando allí mismo que dicha autorización no puede entenderse como "la renuncia al derecho fundamental del que se trata”, ya que la injusta apropiación, publicación, exposición, reproducción y comercialización de la imagen de una persona "afecta lo que en estricto rigor constituye un derecho o bien personalísimo".

Frente al uso de las imágenes de la masajista en Facebook, la Corte aclaró que se vieron vulnerados los derechos al buen nombre y a la honra de la actora, como consecuencia de la negativa de la empresa a retirarlas de la red social Facebook y otros medios de publicidad, por dos razones: primera, porque las imágenes y su publicación en la página de la empresa distorsionan grave y significativamente el concepto público que la actora quiere proyectar y representar, al punto que la continuidad de la publicación de sus imágenes le impide desarrollar su opción de vida y sus expectativas; segunda, porque las fotos difunden una imagen de la demandante entre un universo de públicos indeterminados que tienen acceso a la página de la demandada en la red social y con quienes la accionante no desea compartir su imagen y menos aún permitir que se expresen sobre esta.

Por lo anterior la Corte declara que los acuerdos de uso de imagen no son absolutos y que en ellos se debe especificar de manera exacta los usos para los cuales se emplearán las fotografías, toda vez que de no hacerlo habría un uso abusivo de un dato personal que resultaría en la violación de un dato personal sensible y, por ende, daría aplicación al derecho al olvido para hacer su remoción.

En Argentina existe un precedente del derecho al olvido de mayor envergadura. Es el caso de 
la modelo María Belén Rodríguez, quien demandó a Google y a Yahoo por el uso indebido y no autorizado de su imagen, lo que resultó en la obligación legal de los buscadores de eliminar la imagen de la modelo de sus páginas.

La modelo promovió una acción por daños y perjuicios contra Google Inc. y Yahoo Argentina, alegando que estas habían hecho un uso comercial y no autorizado de la imagen, al haber circulado sus fotografías en sus respectivos buscadores y que se habían aprovechado de sus derechos personalísimos al haber vinculado su imagen a determinadas páginas de Internet de contenido erótico y pornográfico. La Corte Suprema de la Nación concedió las pretensiones de la demanda al considerar que existía negligencia culpable de los buscadores "al no proceder a bloquear o impedir de modo absoluto la existencia de contenidos nocivos o ilegales perjudiciales a los derechos personalísimos de la actora, a partir de serles comunicada la aludida circunstancia" (María Belén Rodríguez vs. Google Inc, y Yahoo Argentina, 2014), lo que violaba sus derechos fundamentales entre ellos el de habeas data, razón por la cual se condenó a los buscadores a aplicar el derecho al olvido de la parte demandante, y por consiguiente a eliminar sus fotografías de las conexiones con páginas pornográficas.

El precedente antes mencionado pone de presente que el derecho al olvido o a la eliminación de los datos personales es un tema que se está volviendo recurrente en la justicia de Latinoamérica y el mundo. Considero importante resaltar el tema de las fotografías, ya que este es uno de los datos que más circula en las redes sociales y en los nuevos medios, pero además, porque es el ejemplo perfecto para evidenciar que no hay limitaciones para la aplicación de este derecho, por cuanto este sobrepasa el derecho del creador o titular de la fotografía, de quien tenga los derechos de imagen o de quien los use aún con autorización.

\section{CONCLUSIÓN}

Después de analizar en profundidad las fuentes nacionales e internacionales del derecho al olvido, es posible afirmar que Colombia fue pionera en el desarrollo de este concepto, pues tiene sus inicios en 1992, año anterior a todos los documentos analizados en este artículo.

Frente al desarrollo de este derecho, es pertinente aclarar que solo la Propuesta de Reglamento General de Protección de Datos lo incluye de manera directa en una legislación, ya que Colombia a pesar de haber desarrollado este principio por vía jurisprudencial no lo incluyó de modo directo en ninguna de sus leyes sobre la materia.

Colombia, al igual que la Directiva 95/46 de la Comisión Europea, los documentos de la onu y de la OECD, a pesar de no incluir este derecho de manera directa, sí incluye los principios de necesidad, finalidad y temporalidad, los cuales podrían derivar en una aplicación del derecho al olvido, pues su utilización tendría los mismos efectos.

A pesar de que en Colombia y el mundo el derecho al olvido tuvo un gran desarrollo en los años 
noventa, la verdadera importancia de este derecho la observaremos en los años venideros, pues en nuestra opinión será la herramienta de protección de los consumidores de redes sociales e Internet. Ello, por cuanto la magnitud de las redes sociales conlleva el manejo de datos a gran nivel, lo que impide que haya un control total sobre la publicación, corrección y supresión de datos, que amenaza gravemente la integridad de los usuarios.

Esta es la razón por la cual creo que en un futuro la legislación y la jurisprudencia sobre el derecho al olvido crecerán de manera abundante, lo que diversificará su aplicación y la concepción de los parámetros señalados en este trabajo. Y a pesar de que los principales opositores reclamen que es ridículo borrar y reescribir la historia, lo cierto es que hay indiscutibles datos negativos y no negativos que con un uso inadecuado pueden afectar todos los derechos fundamentales de una persona y su familia, ya que como se dijo al comienzo de este artículo: "Quien controla el pasado, controla el futuro. Quien controla el presente controla el pasado."

\section{Referencias}

1. Agencia Española de Protección de Datos. (23 de abril de 2014). Contribución de la Agencia Española de Protección de Datos a la Consulta de la Comisión sobre un enfoque global de la protección de datos personales en la Unión Europea. Obtenido de agpd: http://www.agpd.es/portalwebAGPD/canaldocumentacion/textos_interes/common/ pdfs/aepd_dpa_es.pdf
2. Asociación Profesional Española de Privacidad. (s. f.). Propuesta de reglamento europeo sobre protección de datos. Recuperado el 23 de abril de 2014 de ceoe.es: http:// www.ceoe.es/resources/image/propuesta_ reglamento_ue_proteccion_datos.pdf

3. Comisión Europea. (2012). Propuesta del Parlamento Europeo y del Consejo relativa a la protección de las personas físicas en lo que respecta al tratamiento de datos personales y a la libre circulación de estos datos (Reglamento general de protección de datos). Recuperado el 23 de abril de 2011 de eur.lex: http://eur-lex.europa.eu/LexUriServ/LexUriServ.do?uri=COM:2012:0011:FI $\mathrm{N}: \mathrm{ES}: \mathrm{PDF}$

4. Corte Constitucional de Colombia. Sentencia C-1011 de 2008 (M. P.: Jaime Córdoba Triviño; octubre 16 de 2008.

5. Corte Constitucional de Colombia. Sentencia C-748 de 2011 (M. P.: Jorge Ignacio Pretelt Chaljub; octubre 6 de 2011).

6. Corte Constitucional de Colombia. Sentencia de Unificación SU-082 de 1995 (M. P.: Jorge Arango Mejía; marzo 1 de 1995).

7. Corte Constitucional de Colombia. Sentencia T-414 de 1992 (M. P.: Ciro Angarita Barón; junio 16 de 1992).

8. Corte Constitucional de Colombia. Sentencia T-176 de 1995 (M. P.: Eduardo Cifuentes Muñoz; abril 24 de 1995). 
9. Corte Constitucional de Colombia. Sentencia T-471 de 1999 (M. P.: José Gregorio Hernández Galindo; julio 6 de 1999).

10. Corte Constitucional de Colombia, Sentencia T-729 de 2002 (M. P.: Eduardo Montealegre Lynett; septiembre 5 de 2002).

11. Corte Constitucional de Colombia. Sentencia C-185 de 2003 (M. P.: Eduardo Montealegre Lynett; marzo 4 de 2003).

12. Corte Constitucional. Sentencia de tutela T-487 de 2004 (M. P.: Jaime Araújo Rentería; mayo 20 de 2004).

13. Corte Constitucional de Colombia. Sentencia T-405 de 2007 (M. P.: Jaime Córdoba Triviño; mayo 24 de 2007).

14. Corte Constitucional de Colombia. Sentencia T-260 de 2012 (M. P.: Humberto Antonio Sierra Porto; marzo 29 de 2012).

15. Corte Constitucional de Colombia. Sentencia SU-458 de 2012 (M. P.: Adriana María Guillén Arango; junio 21 de 2012).

16. Corte Constitucional de Colombia. Sentencia T-634 de 2013 (M. P.: María Victoria Calle Correa; septiembre 13 de 2013).

17. Corte Suprema de la Nación Argentina. Sentencia María Belén Rodríguez vs. Google Inc. y Yahoo Argentina. 8 de octubre de 2014. Disponible en http://www.telam.com.ar/ advf/documentos/2014/10/544fd356a1 da8.pdfDecreto 1377 de 2013
18. Organización de Estados Americanos [OEA]. (Octubre 17 de 2011). Principios y recomendaciones preliminares sobre la protección de datos. (La protección de datos personales). Obtenido de oas: http://www.oas.org/ es/sla/ddi/docs/CP-CAJP-2921-10_rev1_ corr1.pdf

19. Organization for Economic Cooperation and Development. (2013). The OECD Privacy Framework. Obtenido de oecd: http:// www.oecd.org/sti/ieconomy/oecd_privacy_ framework.pdf

20. Puccinelli, O. (2012). El "derecho al olvido" en el derecho a la protección de datos. El caso argentino. Revista Internacional de Protección de Datos Personales, (1).

21. Red Iberoamericana de Protección de Datos. (s. f.). Declaración del XI Encuentro de la Red Ibearoamericana de Protección de Datos. Obtenido de redipd: http://www.redipd.org/documentacion/common/declaracion_2013_XI_encuentro_es.pdf

22. Sempere, F. J. (Junio 25 de 2013). Caso “Google" sobre el derecho al olvido: ¿Cómo afecta a la propuesta de Reglamento de Protección de Datos? Obtenido de privacidadlogica: http://www.privacidadlogica. es/2013/06/25/caso-google-sobre-elderecho-al-olvido-como-afecta-a-la-propuesta-de-reglamento-de-proteccion-de-datos/ 
23. Supervisor Europeo de Protección de Datos. (2011). Dictamen del Supervisor Europeo de Protección de Datos sobre la Comunicación de la Comisión al Parlamento Europeo, al Consejo, al Comité Económico y Social Europeo y al Comité de las Regiones - "Un enfoque global de la protección de los datos personales en la Unión Europea". [COM(2010) 609 final]. Diario Oficial de la Union Europea, C 248/123. 